\title{
Correspondence:
}

\section{Post-prandial laboratory hypoglycaemia- apparent or real?}

Sometimes laboratory reports show lower postprandial glucose than the fasting glucose in venous plasma, which may even be in the hypoglycaemic range (i.e., $<54 \mathrm{mg} / \mathrm{dL}$ ), thereby giving rise to allegations of switching of the two samples or of laboratory incompetence. Similar results may be seen in an oral glucose tolerance test (GTT). Indeed in a study ${ }^{1}$ of 650 subjects undergoing $100 \mathrm{~g}$ GTT, the lower $25^{\text {th }}$ centile value of 2 hour plasma glucose was 54 $\mathrm{mg} / \mathrm{dL}$, while the $5^{\text {th }}$ centile value was $43 \mathrm{mg} /$ dL. None had any symptoms of hypoglycaemia. This is believed to occur because of the highly efficient extraction of glucose (caused by enhanced insulin secretion in response to oral carbohydrate) by the metabolizing tissues in the postprandial state, so that the venous plasma glucose becomes low, while the arterial plasma glucose remains normal. This widened and variable arterio-venous difference in glucose in the post-prandial state makes it impossible to assign a lower cutoff for post-challenge venous plasma glucose values during the GTT, a point which was highlighted in a study ${ }^{2}$ where lower post-prandial blood glucose levels were observed in healthy individuals when compared to their fasting blood glucose levels.

This is not to suggest that hypoglycaemia can never occur in the postprandial state. However, in such cases the patients will have symptoms concomitant with the low venous plasma glucose readings and the symptoms will be relieved by the intake of food or glucose i.e., the Whipple's triad is fulfilled. Enhanced presumably compensatory epinephrine response produces the classic signs and symptoms of hypoglycaemia such as trembling, sweating, nausea, rapid pulse, light headedness, hunger and epigastric discomfort. Therefore a diagnosis of post prandial hypoglycaemia should not be made on the basis of seemingly low blood glucose concentrations during GTT in the absence of associated symptoms of hypoglycaemia.

In patients with diabetes mellitus receiving insulin secretagogues or short acting insulin, postprandial levels may be lower than fasting due to administration of the medication prior to the breakfast- the low post-prandial values corresponding with the peak activity of the drug. By far the commonest cause of spontaneous postprandial hypoglycaemia is "reactive" hypoglycaemia, wherein there is initial postprandial hyperglycaemia, in response to which, the pancreas mounts a delayed and excessive insulin secretory response leading on to late postprandial hypoglycaemia. Such patients are prone to develop diabetes mellitus later. A similar mechanism underlies the postprandial hypoglycaemia associated with partial gastrectomy- wherein the loss of pylorus leads to rapid movement of food into the small intestine and its absorption there from leading on to initial hyperglycaemia followed by reactive hypoglycaemia at 1.5 to 3 hours after the meal. Rare disorders associated with postprandial hypoglycaemia in adults include autoimmune hypoglycaemia with anti-insulin antibodies, insulinoma or non-insulinoma pancreatogenous hypoglycaemia. Children can have postprandial hypoglycaemia due to hereditary fructose intolerance or galactosaemia. ${ }^{3,4}$ Since disorders associated with spontaneous post prandial hypoglycaemia are rare, such a diagnosis should be made with caution i.e., only after confirming the presence of Whipple's triad and ruling out the use of insulin or sulphonylureas. This will avoid costly investigations and inappropriate therapy. 


\section{REFERENCES}

1. Lev-Ran A, Anderson RW. The diagnosis of postprandial hypoglycemia. Diabetes 1981;30:996-9.

2. Saha B. Post prandial plasma glucose level less than the fasting level in otherwise healthy individuals during routine screening. Indian J Clin Biochem 2006;21:67-71.

3. Glucose homeostasis and hypoglycemia. Cryer PE. In: Kronenberg HM, Melmed S, Polonsky KS, Larsen PR, editors William's textbook of endocrinology. 11th ed. Noida: Saunders Elsevier;2008:1526-7.
4. Carbohydrates.Sacks DB. In: Burtis CA, Ashwood ER, Bruns DE, editors. Tietz textbook of clinical chemistry and molecular diagnostics. 4th ed. New Delhi: Saunders Elsevier;2006:864-7.

\section{T.Chandrasekhar, ${ }^{1}$}

Y.Naresh, ${ }^{1}$

M.M.Suchitra, ${ }^{1}$

V.Suresh. ${ }^{2}$

${ }^{1}$ Departments of Biochemistry,

${ }^{2}$ Endocrinology and Metabolism

Sri Venkateswara Institute of Medical Sciences,

Tirupati

Received: 29 May, 2012.

Chandrasekhar T, Naresh Y, Suchitra MM, Suresh V. Post prandial laboratory hypoglycaemia- apparent or real? J Clin Sci Res 2012;3:153-4. 